\title{
The May 2012 Pianura Padana Emiliana seismic sequence: INGV strong-motion data website
}

\author{
Marco Massa, Sara Lovati, Rodolfo Puglia, Gabriele Ameri, Dario Sudati, Emiliano Russo, \\ Gianlorenzo Franceschina, Lucia Luzi, Francesca Pacor, Paolo Augliera
}

Istituto Nazionale di Geofisica e Vulcanologia, Sezione di Milano/Pavia, Milano, Italy

\author{
Article history \\ Received June 7, 2012; accepted July 11, 2012. \\ Subject classification: \\ ISMD, DYNA, Strong-motion data processing, Data archive.
}

On May 20th 2012, at 02:03:52 UTC, a $\mathrm{M}_{\mathrm{L}} 5.9$ (Mw 6.0) earthquake struck northern Italy (http:// cnt.rm.ingv.it/). The epicentre was localized at $44.89^{\circ} \mathrm{N}$ and $11.23^{\circ} \mathrm{E}$, in an area among the cities of Ferrara, Modena and Mantova. The event occurred at a depth of about $6.3 \mathrm{~km}$, and was characterized by a reverse focal mechanism (http: / / cnt.rm.ingv.it/ tdmt.html/). From May 20th, thousand of earthquakes, the strongest of which with a $\mathrm{M}_{\mathrm{L}} 5.8$ (May 29th, 07:00:03 UTC), occurred in the same area (http: / / iside.rm.ingv.it/).

This note presents a new web site, www.mi.ingv.it/ISMD / ismd.html/ (Figure 1) that includes about 2000 three-component strong-motion recordings of the events with $4.0 \leq \mathrm{M}_{\mathrm{L}}$ $\leq 5.9$ occurred in the central part of the Pianura Padana Emiliana (northern Italy) from May 20th to June 12th. The data come from all INGV strong-motion stations installed in northern Italy (i.e. strong-motion stations of the National Seismic Network, RSN [Amato and Mele 2008]; Strong-Motion Network of Northern Italy, RAIS, http: / / rais.mi.ingv.it/ [Augliera et al. 2011]) and selected with a minimum latitude of $43.5^{\circ} \mathrm{N}$. The earthquake locations reported in the web site come from the National Earthquake Centre of INGV (http: / / cnt.rm.ingv.it/).

An automatic procedure was developed in order to publish in the web site both metadata (processed by an automatic system) and downloadable waveforms in ascii format (uncorrected version). After each earthquake occurrence, the procedure downloads 5 minutes (starting from the event origin time, provided by the National Earthquake Centre) of MINI-Seed waveforms from EIDA (http: / / eida.rm.ingv.it/) archive and applies a fast processing and data analysis tool.

The automatic data processing includes: i) a first-order baseline operator applied to the entire record, in order to have a zero-mean signal; ii) a baseline correction, in order to remove the linear trend, computed with a least square method; iii) tapering of the signal through a cosine function $(0.01 \%)$ at the beginning and at the end of each selected window; iv) the application of a 4th order Butterworth band-pass acausal [Boore and Akkar 2003, Boore and Bommer 2005] filter in order to remove the high and low-frequency noise, the filter cut-off thresholds are automatically selected on the basis of the event magnitude (i.e., $0.1-40 \mathrm{~Hz}$ for $\mathrm{M}_{\mathrm{L}} \geq 5.5$; 0.2-35 $\mathrm{Hz}$ for $4.5 \leq \mathrm{M}_{\mathrm{L}}<5.5 ; 0.3-35 \mathrm{~Hz}$ for $3.5 \leq \mathrm{M}_{\mathrm{L}}<4.5$ ).

Considering the instrumental features of the analysed strong-motion stations (i.e. $155 \mathrm{~dB}+$ Kinemetrics Episensor ES-T, characterized by a flat response up to $200 \mathrm{~Hz}$, coupled with 24 bit analogue to digital recorders) the deconvolution for the sensor response curve is not necessary. Finally, velocity waveforms are obtained through integration of the processed accelerometric data.

For each component of the automatically processed signals PGA (peak ground acceleration), PGV (peak ground velocity) and SA (5\%-damped acceleration response spectra) for periods up to $4 \mathrm{~s}$ are calculated. Moreover, the automatic system provides PSV (5\%-damped pseudo-velocity response spectra), Sd (5\%-damped displacement response spectra), Ia (Arias Intensity) [Arias 1970] and Ih (Housner intensity) [Housner 1952]. In correspondence of each recording site the Horizontal-to-Vertical Spectral Ratio (HVSR) are automatically performed considering $5 \mathrm{~s}$ and $10 \mathrm{~s}$ of $\mathrm{S}$ phase (starting from 1 s before the S-phase onset).

At the end of the automatic procedure, for each event, a web page is generated. The link LIST OF MAIN EVENTS, reported in the left side of the home page (Figure 1), allows to discover further links that lead to the single event webpage (see the list in blue showed in Figure 2). Each event webpage resumes the results obtained by the automatic procedure in terms of static tables (text files), including PGA, PGV, Ia, Ih and SA (at periods of $0.3 \mathrm{~s}, 1.0 \mathrm{~s}, 3.0 \mathrm{~s}$, used for Shakemaps calculation) and generic plots (e.g. location of recording stations, HVSRs, response spectra, accelerograms, comparison between recorded data and Italian Ground Motion Prediction Equations) [Bindi et al. 2011]. For each event 
the strong-motion waveforms are downloadable in raw asciiformat: following the standards proposed by the ITalian ACcelerometric Archive, ITACA (http://itaca.mi.ingv.it/) [Pacor et al. 2011], the ascii files are composed by 43 header lines followed by acceleration data in $\mathrm{cm} / \mathrm{s}^{2}$.

The left side of the home page includes a tool named SEARCHING FOR METADATA. Here the user can generate dynamic output files, in table-format, after a selection based on ground-motion parameters (PGA and PGV), magnitude and distance ranges, Eurocode8 site category [CEN 2003] and time period of interest.

The ISMD web site arose few days after the PadanoEmiliana seismic sequence occurrence, with the aim to collect and distribute the strong-motion data recorded by INGV stations for events with $M_{L} \geq 4.0$. In this way the web site can represent in the next future a new tool essential to ensure high quality accelerograms of immediate use for engineering application and seismological studies. The availability of unprocessed waveforms allows skilful users to perform different data processing on the basis of each specific requirements.

\section{References}

Amato, A., and F. Mele (2008). Performance of the INGV National Seismic Network from 1997 to 2007, Annals of Geophysics, 51 (2-3), 417-431.

Arias, A. (1970). A measure of earthquake intensity, In: R. Hansen (ed.), Seismic Design of Nuclear Power Plants, M.I.T. press, Cambridge.

Augliera, P., M. Massa, E. D'Alema and S. Marzorati (2011). RAIS: a real time strong-motion network in northern Italy, Annals of Geophysics, 54 (1), 23-34.

Bindi, D., F. Pacor, L. Luzi, R. Puglia, M. Massa, G. Ameri and R. Paolucci (2011). Ground Motion Prediction Equations Derived from the Italian Strong Motion Data Base, B. Earthq. Eng., 9 (6), 1899-1920.

Boore, D.M., and S. Akkar (2003). Effect of casual and acausal filters on elastic and inelastic spectra, Earthq. Eng. Struct. D., 32, 1729-1748.

Boore, D.M., and J.J. Bommer (2005). Processing of strongmotion accelerograms: needs, options and consequences, Soil Dyn. Earthq. Eng., 25, 93-115.

CEN (2003). European Committee for Standardisation. Eurocode 8: Design of Structures for Earthquake Resistance. Part 1: General Rules, Seismic Actions and Rules for Buildings, European Standard EN 1998-1, Draft 6, Doc CEN/TC250/SC8/N335, Jan 2003, Brussels.

Housner, G.W. (1952). Spectrum Intensities of Strong-Motion Earthquakes, In: C.M. Feigen (ed.), Proc. Symp. Earthquake and Blast Effects Structures, Univ. California, Los Angeles, 21-36.

Pacor, F., R. Paolucci, G. Ameri, M. Massa and R. Puglia (2011). Italian strong motion records in ITACA: overview and record processing. B. Earthq. Eng., 9 (6), 1741-1759.
${ }^{\star}$ Corresponding author: Marco Massa, Istituto Nazionale di Geofisica e Vulcanologia, Sezione di Milano/Pavia, Milano, Italy; email: marco.massa@mi.ingv.it.

(C) 2012 by the Istituto Nazionale di Geofisica e Vulcanologia. All rights reserved. 


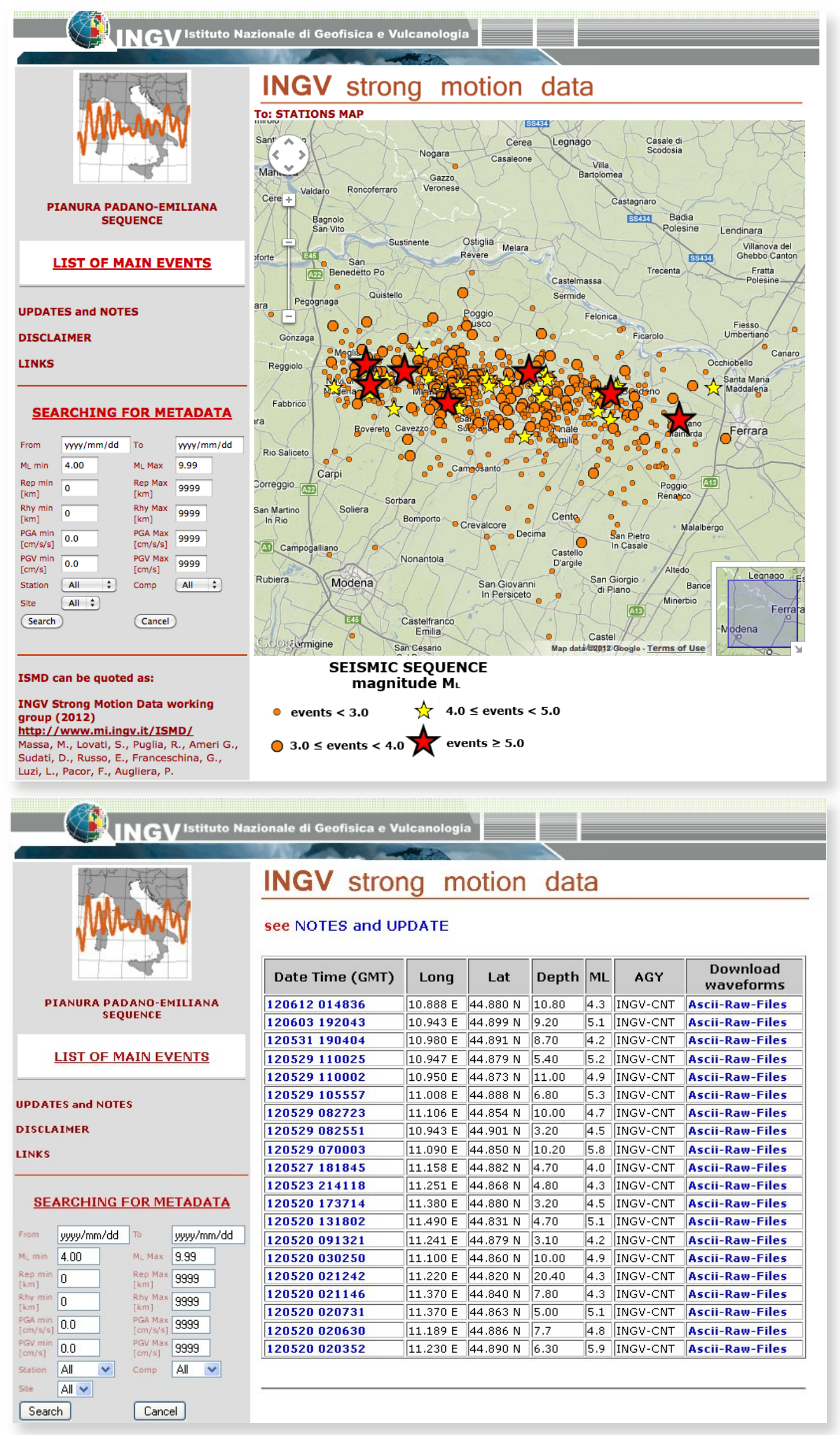

Figure 1 (top). www.mi.ingv.it/ISMD/ismd.html : home page. Figure 2 (bottom). List of main events (from May 20th 2012 to June 12th 2012, $\mathrm{M}_{\mathrm{L}} \geq 4.0$ ). Each line of the list in blue links to the single event web-page. The last column allows the user to download the strongmotion waveforms in ascii format. 